\title{
Ethiopathogenic mechanisms of bronchial asthma
}

\author{
F Muñoz-López* \\ Former Head of the Department of Pediatric Immunoallergology, Hospital Clinic, Faculty of Medicine, University of Barcelona, Spain
}

\begin{abstract}
Asthma is the most frequent respiratory process both in pediatric and adult ages, but when sharing symptoms with other processes, sometimes there are certain diagnostic doubts and especially therapeutic. The distinction is the bronchiospasm crisis due to the existence of bronchial hyperresponsiveness, the origin of which may be genetic, which causes the onset of asthma to be at an early age, or caused by inflammation due to exposure to various environmental or infectious irritants. The pathogenesis of both possibilities is the subject of this review insisting on specifying the diagnosis that will lead to appropriate treatment not always based only on anti-inflammatories.
\end{abstract}

\section{Concept of asthma}

The processes that affect the respiratory system, especially the bronchotracheal tract, are manifested by a series of symptoms common to most of them (cough, wheezing dyspnea, expectoration). In addition to these symptoms, the diagnosis of asthma is based on the existence of acute episodes of dyspnea (dyspnea crisis) that are not common in any of the other processes, a concept maintained over the years [1-3]. The bronchial hyperresponsiveness (BHR), is responsible for acute and sporadic bronchiospasm, that is, the aforementioned episodes of dyspnea. The other symptoms, not sporadic, but habitual, of greater or less intensity depending on the gravity, environment and treatment, are mainly due to the inflammation that accompanies the process, whose cause differs in different circumstances. The concept of bronchial hyperresponsiveness was introduced towards the year 1960 and in the 1970s inflammation was favored as a dominant factor in the etiopathogenesis of asthma, and is currently the criterion that dominates in the definition of the process, therefore, it is treated of an inflammatory disease. However, despite the fact that inflammation is currently considered the main cause of asthma, the concept of the disease can not be disconnected from the aforementioned existence of acute episodes of dyspnea, so when they do not exist, since there is no evidence of BHR, the diagnosis of asthma is doubtful, so it is necessary to think about other possible processes of the respiratory apparatus (Table 1).

Bronchial hyperresponsiveness may be genetic, concomitant with the inheritance of the allergic, or acquired, secondary to bronchial inflammation, as a consequence of prolonged exposure to environmental irritants and also by infectious processes affecting the respiratory tract, concepts that correspond to the already unusual concepts of extrinsic asthma and intrinsic asthma respectively.

\section{Genetic predisposition}

\section{Chromosomes and genes involved}

The allergic predisposition (atopic) is of a polygenic nature, that is to say, the genes that support the polymorphisms that give rise to the body's abnormal response to substances (allergens) that are well tolerated by most people, and which originate the production of specific IgE antibodies (reagins) against proteins with antigenic capacity contained therein. Even with no atopic predisposition, at any age, excessive exposure to allergens equally can cause specific IgE production, with consequent clinical translation.

The genetic basis of asthma is not unique, but depends on a complex polymorphism and it is not strange that the involvement of the various genes that are supposed to be implicated is not yet known. The allergic reaction is linked to the predominance of Th2 lymphocyte activity and the subsequent increase in specific IgE. Chromosome 11 (11q13) was the first to identify genes involved in its production; in it lies the synthesis of the $\beta$ chain of the high affinity IgE receptor.

It is estimated that at least one hundred genes are involved in the pathogenesis of atopy and asthma. Some 30 locus on various chromosomes have been linked on the one hand with the function of the airways and another on the production of IgE $[4,5]$. Chromosome

Table 1. Common tracheobronchial symptoms and more frequent processes. (others that asthma)

\begin{tabular}{|l|l|l|l|}
\hline Cough & Whistlingrales & Dyspnea & Expectoration \\
\hline Rhinofharyngitis & Tracheobronchitis & Wheezing bronchitis & Chronic Bronchitis \\
Sinusitis & Foreignbody & Bronchiolitis & Bronchiectasis \\
Adenoiditis & Mucoviscidosis & Gastro- oesophageal & Pneumonia \\
Whooping cough & Bronchiectasis & reflux & Mucoviscidosis \\
Tracheobronchitis & Hemosiderosis & $\begin{array}{l}\text { Extrinc allergic } \\
\text { alveolitis }\end{array}$ & Hemosiderosis \\
Laryngitis & Cymphadenopathy & COPD \\
Bronchitis & Pulmonary cysts & Extra- & \\
Bronchiectasis & Immotile-cilia & tracheobronchial: & \\
Foreign body & syndrome & -Pleuritis & \\
Gastro- & Lobular emphysema & -Pneumonia & \\
oesophagealreflux & Tracheoesophageal & -Tuberculosis & \\
Inhalation of & fistula & -Pulmonary edema & \\
irritating gases & Eosinophilic & -Etc. & \\
Eosinophilic & bronchitis & & \\
bronchitis & & & \\
COPD & & & \\
Psychogenic & & & \\
\hline
\end{tabular}

*Correspondence to: Francisco Muñoz-López, Former Head of the Department of Pediatric Immunoallergology, Hospital Clinic, Faculty of Medicine, University of Barcelona, Spain, E-mail: 5314fml@comb.cat

Key words: asthma, genetic, bronchial hiperresponsiveness, small airways, immunotherapy

Received: May 10, 2017; Accepted: June 09, 2017; Published: June 13, 2017 
5 (5q31-q33) contains the genes that modulate the production of interleukins secreted by Th2 lymphocytes, such as IL-4 and IL-13 responsible for the atopic response when involved in the secretion of IgE by B lymphocytes (plasma cells), as well as other interleukins (IL-3, IL-5, IL-9) which also intervene In addition, in the same gene has been identified the protocadherin-1 (PCDH1) that could alter the integrity of the bronchial epithelium, the first line of defense against inhalation of environmental substances [6]. On the other hand, the onset of asthma in the pediatric age has linked to chromosome 17q21 the main genetic determinant of the ORMDL3 gene that encodes endoplasmic reticulum proteins and has also been associated with poor outcome in children exposed to environmental irritants, especially tobacco smoke $[7,8]$.

Logically, genes related to the allergic reaction are common to other allergic processes, such as those caused by food or drugs mainly, which may be the cause of dermatological (eczema, urticaria), digestive or anaphylactic processes. Sometimes, because of the same, there is allergic rhinitis, but it must be taken into account that it is not always an exclusive manifestation of the allergy, but at the same time the genes involved in the pulmonary function (bronchial hyperresponsiveness: BHR) can intervene. In these cases, rhinitis precedes asthma, as in many cases eczema manifests itself early in infants who later suffer from asthma.

\section{Bronchial hiperresponsiveness}

Familial congenital BHR is the consequence of several mutations in the genes encoding $\beta 2$-adrenergic receptors of the bronchial smooth muscle, related to the greater sensitivity of the same in the people affects due to the mutation. The consequence of this mutation is the $\alpha$-adrenergic (constrictor) / $\beta$ adrenergic (relaxant) imbalance, which leads to constrictor predominance, which has led to the use of $\beta_{2^{-}}$ mimetics as effective bronchodilators. In addition, mast cells have been demonstrated in the bronchial smooth muscle of these patients, which undoubtedly have a predominant role in the hyperresponsiveness when are relapsed the mediators responsible for bronchial smooth muscle constriction and the attraction of eosinophils and neutrophils (histamine, tryptase, chymase) and later those involved in the inflammatory reaction (leukotrienes, prostaglandins, thromboxanes) $[9,10]$.

The acquired BHR is the result of exposure to various environmental agents, but also to infectious processes of the airways, as it happens especially in the early childhood. At this age, such infections are common and are usually diagnosed as having wheezing bronchitis, without subsequently causing sequelae. However, even in the absence of atopic predisposition, recurrence of such infections can cause inflammation with consequent BHR which also in the pediatric age may be caused by overexposure to environmental irritants, including tobacco smoke [11].

Excessive exposure to environmental irritants is the more important cause of occupational asthma. Two circumstances may occur, that the patient has no allergic predisposition or that it is not very prominent because it has no atopic antecedents from the parents, but from other relatives. In these patients, habitual contact with animals, plants or foodstuffs, whose proteins are IgE, eosinophils and other cellular components (eosinophilic inflammation). Even in these cases of low atopic predisposition it has been shown that manual manipulation of proteins (eg ovalbumin) may be the source of the production of BHR.

In the absence of allergic predisposition, exposure to irritants of low molecular weight, will produce neutrophilic inflammation (serum IgG and abundant neutrophils in sputum) and lesion of the bronchial epithelium with consequent exposure to cholinergic nerve endings whose stimulation by the irritants will be the basis of BHR (occupational asthma) [12-15].
In both modalities of BHR the bronchial smooth muscle and the small airways play a primordial role in relation to the inflammatory process that takes place after the action of the pneumoallergens, in the case of the primary BHR, or after the exposure to the cited environmental factors, which are the main cause of secondary BHR. In all cases, the smooth muscle is thickened either by hypertrophy or hyperplasia, that is, the increase in the number of cells that will produce many mediators responsible for inflammation, such as adhesion molecules and integrins that facilitate the contact between the cells involved in the inflammation, demonstrating that the process is characteristic of asthma but not of other chronic airway processes [16]. Also, when the process is allergic, the smooth muscle contracts as a consequence of stimuli caused by some of the mediators of the allergic reaction mainly from mast cells, since on the muscular surface there are receptors for histamine, cysteinyl-leukotrienes and prostaglandins, as well as for $\alpha$-adrenergic receptors, acetylcholine and adrenaline.

The small airways, represented in the spirometric curve by the space $\mathrm{FEF}_{25-75}$, (midexpiratory phase) constitute the $99.9 \%$ of the bronchial tree, in correspondence to the continuous bronchial branch that gives rise to increasingly smaller bronchi, in whose 7th to 19th division, the inner diameter oscillates between 0.5 and $2 \mathrm{~mm}$. The evaluation by the methacholine or histamine test, is fundamental to know the real state of bronchial hyperresponsiveness $[17,18]$.

\section{Therapeutic implications}

In any case, there are three points on which it is based: Symptomatic: bronchodilators, expectorants, antitussives. Pathogenic: antihistamines, antileukotrienes, anti-inflammatories (inhaled or oral corticosteroids). But above all, etiological, starting with the elimination of allergens and environmental irritants, or at least, reduction of them or protection against them (domicile, work), but above all, indicated immunotherapy provided that the responsible allergens are known and that there are no complications that discard it, and should start as soon as possible, especially in childhood. Through a complex mechanism it is possible to balance the action of the Th1/Th2 lymphocytes by stopping the production and activity of allergen-specific IgE, which avoids new sensitizations as it happens in the majority of patients, so the long-term prognosis is highly satisfactory [19].

\section{References}

1. American Thoracic Society Committee on Diagnostic Standards Definitions and classification of chronic bronchitis, asthma and pulmonary emphysema. Am Rev Respir Dis 85: 762.

2. Hargreave FE, Nair P (2009) The definition and diagnosis of asthma. Clin Exp Allergy 39: 1652-1658. [Crossref]

3. James DR, Lyttle MD (2016) British guideline on the management of asthma: SIGN Clinical Guideline 141, 2014. Arch Dis Child Educ Pract Ed 101: 319-322. [Crossref]

4. Binia A, Kabesch M (2012) Respiratory medicine - genetic base for allergy and asthma. Swiss Med Wkly 142: w13612. [Crossref]

5. Kabesch M (2010) Novel asthma-associated genes from genome-wide association studies: what is their significance? Chest 137: 909-915. [Crossref]

6. Koppelman GH, Meyers DA, Howard TD, Zheng SL, Hawkins GA, et al (2009) Identification of PCDH1 as a novel susceptibility gene for bronchial hyperresponsiveness. Am J Respir Crit Care Med 180: 929-935. [Crossref]

7. Moffatt MF, Kabesch M, Liang L, Dixon AL, Strachan D, et al. (2007) Genetic variants regulating ORMDL3 expression contribute to the risk of childhood asthma. Nature 448: 470-473. [Crossref]

8. Bouzigon E, Corda E, Aschard H, Dizier MH, Boland A, et al. (2008) Effect of 17q21 variants and smoking exposure in early-onset asthma. N Engl J Med 359: 1985-1994. [Crossref] 
9. Brightling CE, Bradding P, Symon FA, Holgate ST, Wardlaw AJ, et al. (2002) Mastcell infiltration of airway smooth muscle in asthma. $N$ Engl J Med 346: 1699-1705. [Crossref]

10. Alkhouri H, Hollins F, Moir LM, Brightling CE, Armour CL, et al. (2011) Human lung mast cells modulate the functions of airway smooth muscle cells in asthma. Allergy 66: 1231-1241. [Crossref]

11. Muñoz-López F (2014) Bronchial hyperresponsiveness and asthma in the pediatric population. Allergol et Immunopathol. 42/3:230-234.

12. Sastre J, Vandenplas O, Park HS (2003) Pathogenesis of occupational asthma. Eur Respir J 22: 364-373. [Crossref]

13. Mapp CE (2003) The role of genetic factors in occupational asthma. Eur Respir J 22: 173-178. [Crossref]

14. Canning BJ (2006) Reflex regulation of airway smooth muscle tone. $J$ Appl Physiol (1985) 101: 971-985. [Crossref]
15. Bossé Y, Rousseau E, Amrani Y, Grunstein MM (2013) Smooth muscle hypercontractility in airway hyperresponsiveness: innate, acquired, or nonexistent? $J$ Allergy (Cairo) 2013: 938046. [Crossref]

16. Black JL, Roth M (2009) Intrinsic asthma: is it intrinsic to the smooth muscle? Clin Exp Allergy 39: 962-965. [Crossref]

17. Muñoz-López F, Rios-Alcolea M (2012) The interest of FEF25-75 in evaluating bronchial hyperresponsiveness with metacholine test. Allergol Immunopathol (Madr) 40: 352-356. [Crossref]

18. Sposato B, Scalese M, Migliorini MG, Di Tomassi M, Scala R (2014) Small airway impairment and bronchial hyperresponsiveness in asthma onset. Allergu Asthma Immunol Res 6: 242-251. [Crossref]

19. Wesley Burks A, Calderon MA, Casale T, Cox L, Demoly P, et al. (2013) Update on allergy immunotherapy: American Academy of Allergy, Asthma \& Immunology/ European Academy of Allergy and Clinical Immunology/PRACTAL consensus. J Allergy Clin Immunol 131: 1288-1296. [Crossref]

Copyright: (C2017 Muñoz-López F. This is an open-access article distributed under the terms of the Creative Commons Attribution License, which permits unrestricted use, distribution, and reproduction in any medium, provided the original author and source are credited. 